\section{Caring at night for people with multiple sclerosis}

\author{
A J Spackman, D C Doulton, M H W Roberts, \\ J P Martin, D L McLellan
}

University Rehabilitation Unit and Department of Sociology and Social Policy, University of Southampton,

Southampton

A J Spackman, PHD, senior research fellow

M H W Roberts, MRCP, research registrar

J P Martin, PHD, professor of social policy

D L McLellan, FRCP, professor of rehabilitation

University of Southampton Computing Service

D C Doulton, BA, senior programmer

Correspondence to: Dr A J Spackman, Institute for Health Policy Studies, Faculty of Social Sciences, Murray Building, Southampton University, Southampton SO9 5NH.

BrMed f 1989;299:1433

\author{
Department of Child \\ Health, University \\ Hospital, Nottingham \\ NG7 2UH \\ C O'Callaghan, MRCP, \\ lecturer in child health \\ A D Milner, FRCP, professor \\ of paediatric respiratory \\ medicine \\ A Swarbrick, SEN, respiratory \\ nurse
}

\section{Correspondence to: \\ Dr C O'Callaghan.}

BrMed f 1989;299:1433-4
Although there have been many studies of informal carers, ' few have studied substantial numbers of subjects or specific conditions. The Southampton multiple sclerosis survey is based on all people in the health authority with confirmed multiple sclerosis. We investigated whether relatives caring for these people had to perform care activities at night.

\section{Subjects, methods, and results}

Three hundred and five people with multiple sclerosis (207 women, 98 men; $74 \%$ of those identified) were interviewed by the research physician (MHWR). in the community were interviewed by the research sociologist (AJS). The 229 relatives interviewed comprised 194 spouses or cohabitees, 22 parents, and 13 offspring or siblings. The ratio of husbands and male cohabitees to wives and female cohabitees was $2: 1$, but the overall sex ratio was 132 men to 97 women owing to the number of mothers, daughters, and sisters given as nearest relatives.

Most of the close relatives were not carers in the sense used in the survey, in which the term was restricted to people regularly helping a person with multiple sclerosis with at least one personal, domestic, or social care activity from a specified list. Eighty relatives met this definition. Each was asked to keep a 24 hour diary listing and timing all care activities undertaken. The 74 who did so lived at the same address as the person with multiple sclerosis for whom they cared, and 66 were spouses or cohabitees. Their mean age was 57 , and 25 were 65 or older. The people being cared for were moderately or severely disabled, scoring $\geqslant 5.0$ on the Kurtzke expanded disability status scale. ${ }^{2}$ Forty two had periodic urinary incontinence, 32 on a daily basis. None had seen a continence advisory nurse.

Disturbance at night was normal for 52 carers and was recorded by 44 of those who kept diaries, 42 of Whenever possible the nearest relatives of those living

\section{Paradoxical bronchoconstriction in wheezing infants after nebulised preservative free iso-osmolar ipratropium bromide}

\section{O’Callaghan, A D Milner, A Swarbrick}

Nebulised solutions may cause transient paradoxical deterioration in lung function in wheezy infants. ${ }^{\prime}$ The cause of this transient deterioration in infancy is not clear but may be related to the hypo-osmolality, the acidity, or the preservatives in the nebuliser solution. A new iso-osmolar nebuliser solution of ipratropium bromide, free of preservatives, was given to a group of acutely wheezy infants to assess their response.

\section{Patients, methods, and results}

Eleven infants (mean age 9 (SD 3) months) who had been admitted to hospital with an acute episode of whom were the sole carers while two were helped by relatives. None received help from community health or social services. Most disturbances (18) were associated with toiletting; others were to make the people comfortable (10), to help them turn in bed (eight), and to help back to bed those who could get out of bed unaided (eight). Lesser activities included giving drugs, preparing drinks or food, dressing or undressing, and being sociable with those unable to sleep.

Although 31 of the 44 carers spent less than half an hour helping in total, the disturbances tended to be spread throughout the night, averaging 2.6 per carer. During the day the carers spent a mean of five and a half hours on caring activities.

\section{Comment}

Caring for people with multiple sclerosis not only entailed appreciable amounts of daytime care but meant for $52(70 \%)$ of the carers that nights were interrupted on two or more occasions. Other studies have shown how stressful and poorly tolerated unremitting nights on call are for carers. ${ }^{34}$ Disturbance at night emphasised the carers' loneliness and social isolation: as one put it, "You look out of the window, all the houses are in darkness, and you realise you are on your own."

How could this strain be reduced? The most obvious help would be to increase the availability of services that offer to sit with people at night. As toiletting was the most common cause of disturbance a review of the management of incontinence might also be useful. Both possibilities should be considered if the informal care is a long term arrangement.

We thank the Multiple Sclerosis Society of Great Britain for funding the research and the carers who participated in the study.

1 Parker G. With due care and attention: a review of research on informal care. London: Family Policy Studies Centre, 1985.

2 Kurtzke JF. Rating neurologic impairment in multiple sclerosis - an expanded disability status scale (EDSS). Neurology 1983;33:1444-52.

3 Levin E, Sinclair I, Gorbach P. The supporters of confused elderly people at home: extract from the main report. London: National Institute for Social Work Research Unit, 1983.

4 Sandford JRA. Tolerance of debility in elderly dependants by supporters at home: its significance for hospital practice. Br Med f 1975;iii:471-3.

(Accepted 14 September 1989) wheezing and who were thought on admission to respond clinically to nebulised ipratropium bromide were studied. All but two had a history of bronchiolitis. All drugs were stopped eight hours before the study. Infants were sedated with chloral hydrate $(120 \mathrm{mg} / \mathrm{kg})$, and thoracic gas volume and airways resistance were measured by total body plethysmography, as detailed elsewhere.' Specific conductance was calculated. After baseline lung function was measured each infant was given nebulised normal saline $(2 \mathrm{ml})$ via a cirrhus nebulising chamber with a flow rate of $61 /$ minute for five minutes. Fifteen minutes later the infants were given $2 \mathrm{ml}$ of ipratropium bromide from the unit dose phial nebulised via the same cirrhus chamber running at the same flow rate for five minutes. Lung function was measured every five minutes until the child awoke. The solutions used were iso-osmolar. The $\mathrm{pH}$ of the normal saline used was $6 \cdot 85$. The $\mathrm{pH}$ of ipratropium bromide from the unit dose phial was $3 \cdot 6$.

Three of the infants awoke during baseline measurements and were not included in the results. The figure shows the individual change in specific conductance in the eight remaining patients after nebulised 


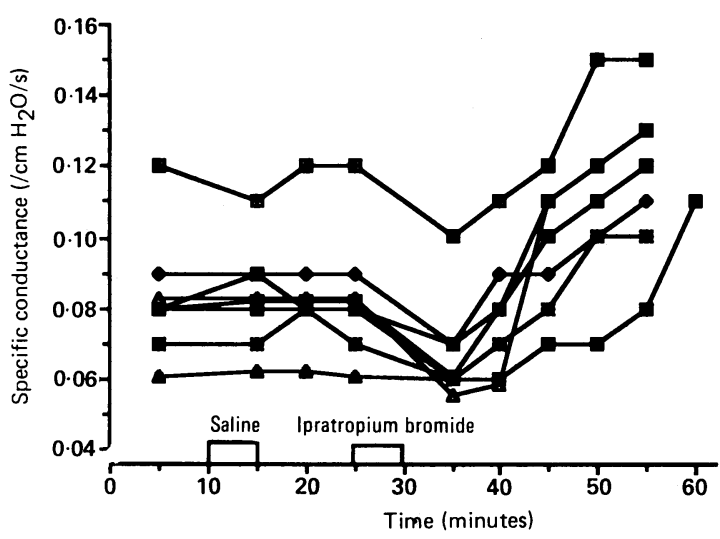

Specific conductance against time after challenge with nebulised normal saline and unit dose phial ipratropium bromide

saline and ipratropium bromide. There was no change in specific conductance after nebulised normal saline. In the group as a whole there was a significant decrease in specific conductance at one minute after nebulisation of the ipratropium bromide (from a mean of $0.083 / \mathrm{cm} \mathrm{H}_{2} \mathrm{O} / \mathrm{s}$ to $0.066 / \mathrm{cm} \mathrm{H}_{2} \mathrm{O} / \mathrm{s} ; \mathrm{p}<0.05$ ). Twenty minutes after nebulisation of ipratropium bromide specific conductance was significantly greater $\left(0 \cdot 11 \mathrm{~cm} \mathrm{H}_{2} \mathrm{O} / \mathrm{s}\right)$ than baseline values $(\mathrm{p}<0 \cdot 05)$. The osmolality of nebulised normal saline changed from 280 to $320 \mathrm{mmol} / \mathrm{kg}$ during nebulisation and that of the nebulised ipratropium bromide from 285 to $318 \mathrm{mmol} / \mathrm{kg}$. There was no change in the $\mathrm{pH}$ of the solutions with nebulisation.

\section{Comment}

Ipratropium bromide nebuliser solution was reformulated in an iso-osmolar form after episodes of bronchoconstriction in adults that were shown to be related to its hypo-osmolality. ${ }^{2}$ The unit dose phial of ipratropium bromide has had preservatives removed and is osmolar. The preservatives present in the previous isotonic ipratropium solution as bacteriostatic and stabilising agents, (benzalkonium chloride and ethylenediaminetetra-acetic acid (EDTA)), cause bronchoconstriction in adult asthmatics.

There are two possible explanations for the bronchoconstriction seen in our infants after ipratropium bromide. Firstly, the unit dose phial solution of ipratropium bromide is acidic, with a $\mathrm{pH}$ of $3 \cdot 6$, and acidic solutions may cause bronchoconstriction. ${ }^{4}$ Secondly, ipratropium bromide is a non-selective anticholinergic drug which blocks prejunctional $\left(\mathrm{M}_{2}\right)$ and postjunctional $\left(\mathrm{M}_{3}\right)$ muscarinic receptors with equal affinity. Blockade of the muscarinic autoreceptor $\left(\mathrm{M}_{2}\right)$ means that more acetylcholine will be released during cholinergic nerve stimulation. This may precede and may overcome postjunctional blockade of the $M_{3}$ receptor. This supports the idea that non-selective muscarinic antagonists might exacerbate bronchoconstriction by an action on prejunctional $\mathrm{M}_{2}$ receptors. Nevertheless, paradoxical bronchoconstriction was not seen in a group of wheezy infants after administration of ipratropium bromide through a metered dose inhaler. ${ }^{5}$ While we cannot directly compare these groups, the results suggest that the acidity of the solution may be related to the paradoxical bronchoconstriction seen.

1 O'Callaghan C, Milner AD, Swarbrick A. Paradoxical deterioration in lung function after nebulised salbutamol in wheezy infants. Lancel 1986;ii:1424-5. 2 Mann JS, Howarth PH, Holgate ST. Bronchoconstriction induced by ipratropium bromide in asthma: relationship to hypertonicity. $\mathrm{Br} \mathrm{Med} \mathcal{F}$ 1984;289:469.

3 Beasley R, Rafferty P, Holgate ST. Bronchoconstriction properties of preservatives in ipratropium bromide (Atrovent) nebulizer solution. preservatives in ipratropit

4 Utall MJ, Marrow PE, Speers DM, Darling J, Hyde RW. Airways response to sulphate and sulphuric acid aerosols in asthmatics. Am Rev Respir Dis sulphate and sulph

5 O'Callaghan C, Milner AD, Swarbrick A. Spacer device with face mask attachment for giving bronchodilators to infants with asthma. Br Med $\mathcal{F}$ 1989;298:160-1.

(Accepted 4 September 1989)

\section{Use of oestrogen replacement therapy in high risk groups in the United Kingdom}

\section{Tim D Spector}

\section{Department of \\ Environmental and Preventive Medicine, St Bartholomew's Hospital Medical College, London EC1M 6BQ \\ Tim D Spector, MRCP, lecturer in epidemiology}

Hormone replacement therapy is used less in the United Kingdom than in North America and other European countries. Recently both the media and medical journals ${ }^{1}$ have urged that it be prescribed for more women in the United Kingdom. To assess the levels of current use I carried out a survey among menopausal women and women who had had a hysterectomy or oophorectomy in three general practices in Greater London.

\section{Subjects, methods, and results}

I obtained the names and addresses of 5025 women aged between 45 and 65 from the practices' age-sex registers. The women were sent a questionnaire that asked whether they had received hormone replacement therapy and if so for how long and when they had started it; and whether they had had a hysterectomy or oophorectomy and for details of any gynaecological operations. Altogether 3238 replied. The table gives the results.

The mean age of the women was 52, and 1858 were no longer having periods. Altogether 330 had received hormone replacement therapy $(10 \%$ of all the respondents and $18 \%$ of the postmenopausal respondents). The mean duration of use was only 21 months (median 11 months) in the women overall and 28 months (median 24) in the women who had had a bilateral oophorectomy.

\section{Comment}

The survey showed that most of the menopausal women questioned had never received hormone replacement therapy and those who had had received it for only short periods. Those who would have benefited most - namely, women after hysterectomy and oophorectomy - had generally not been prescribed it despite a lack of medical contraindications. The practices that I studied were probably reasonably representative of practices in general, and no major differences were noted in their rates of hysterectomy or oophorectomy compared with national rates. ${ }^{2}$

The observations that $70 \%$ of women who had had a

Number (percentage) of menopausal women and women who had had hysterectomy or oophorectomy who had received hormone replacement therapy (HRT)

\begin{tabular}{lcc}
\hline & Total No & Women who had received HRT \\
\hline All women & 3238 & $330(10)$ \\
Women after hysterectomy & 464 & $112(25)$ \\
Women after oophorectomy: & & \\
$\quad$ Unilateral & 112 & $29(26)$ \\
Bilateral & 119 & $36(30)$ \\
Bilateral before age 40 & 31 & $7(23)$ \\
& &
\end{tabular}

